\title{
Agoitrous Graves' Hyperthyroidism with Markedly Elevated Thyroid Stimulating Immunoglobulin Titre displaying Rapid Response to Carbimazole with Discordant Thyroid Function
}

\author{
Yin Chian Kon, ${ }^{1}$ Brenda Su Ping Lim, ${ }^{1}$ Yingshan Lee, ${ }^{1}$ Swee Eng Aw, ${ }^{2}$ Yoko Kin Yoke Wong ${ }^{3}$ \\ ${ }^{1}$ Department of Endocrinology, Tan Tock Seng Hospital, Singapore \\ ${ }^{2}$ Department of Nuclear Medicine and Molecular Imaging, Singapore General Hospital, Singapore \\ ${ }^{3}$ Department of Epidemiology, Singapore Clinical Research Institute, Singapore
}

\begin{abstract}
We characterize the clinical and laboratory characteristics of 5 patients with Graves' thyrotoxicosis whose serum free thyroxine (fT4) concentration decreased unexpectedly to low levels on conventional doses of carbimazole (CMZ) therapy. The initial fT4 mean was $40.0 \mathrm{pM}$, range $25-69 \mathrm{pM}$. Thyroid volume by ultrasound measured as mean $11 \mathrm{ml}$, range $9.0-15.6 \mathrm{ml}$. Initial TSI levels measured $1487 \%$ to $>4444 \%$. Serum fT4 fell to low-normal or hypothyroid levels within 3.6 to 9.3 weeks of initiating CMZ 5 to $15 \mathrm{mg}$ daily, and subsequently modulated by fine dosage adjustments. In one patient, serum fT4 fluctuated in a "yo-yo" pattern. There also emerged a pattern of low normal/low serum fT4 levels associated with discordant low/mid normal serum TSH levels respectively, at normal serum fT3 levels. The longterm daily-averaged $\mathrm{CMZ}$ maintenance dose ranged from $0.7 \mathrm{mg}$ to $3.2 \mathrm{mg}$. Patients with newly diagnosed Graves' hyperthyroidism who have small thyroid glands and markedly elevated TSI titres appear to be "ATD dose sensitive." Their TFT on ATD therapy may display a "central hypothyroid" pattern. We suggest finer CMZ dose titration at closer follow-up intervals to achieve biochemical euthyroidism.
\end{abstract}

Key words: Graves' disease, Thyroid Stimulating Immunoglobulin, responsiveness, carbimazole

\section{INTRODUCTION}

In patients with newly diagnosed Graves' hyperthyroidism started on anti-thyroid drugs (ATDs), various factors affect the rate of decrease of serum free thyroxine (fT4) concentrations. Current guidelines recommend the initial starting dose of ATD to be based on a number of factors, such as initial serum fT4 concentration, thyroid gland size and triiodothyronine (T3) levels. ${ }^{1}$ In a retrospective multivariate analysis by Choi et al., of 99 patients with new onset Graves' disease, high level of fT4, high thyroid stimulating hormone receptor antibody (TRAb) titre and absence of goiter were associated with rapid responsiveness to methimazole treatment. ${ }^{2}$ In their entire cohort, most patients showed normalization of free thyroxine within about 2 months, regardless of the initial free thyroxine level.

Dalan et al., had previously reported on a male patient with newly diagnosed agoitrous Graves' hyperthyroidism who unexpectedly developed severe hypothyroxinemia within 3 weeks of starting anti-thyroid treatment, and rapidly rebounded back to hyperthyroidism within one week of ATD discontinuation. ${ }^{3}$ He demonstrated a highly elevated TRAb titre. Intriguingly, he also demonstrated a discordant profile of suppressed serum TSH level despite concomitantly low serum fT4 and low to normal serum fT3 concentrations during the course of ATD treatment. ${ }^{3}$ A low serum fT4 may prompt the clinician to stop ATD therapy, which leads to rebound thyrotoxicosis. We report the biochemical and clinical features of a further 5 patients with rapid response to ATD. Early recognition of this phenotype can help to avoid swings between hypothyroidism and hyperthyroidism upon commencing and after adjusting ATD therapy.

\section{CASES}

\section{Patients}

We describe 5 patients referred for management of Graves' hyperthyroidism from July 2008 to March 2017 at the Department of Endocrinology, Tan Tock Seng Hospital, Singapore, who developed hypothyroxinemia after starting oral carbimazole (CMZ). This case series has been approved for publication by our institutional review board (DSRB Ref 2014/00896). Serum TRAb, thyroid stimulating immunoglobulin (TSI), TSH, fT4 and fT3 concentrations,
Corresponding author: Yin Chian Kon, BSc (London), MBBS (London), MRCP (UK), FAMS (Endocrinology)

Senior Consultant, Department of Endocrinology, Tan Tock Seng Hospital

11 Jalan Tan Tock Seng, Singapore, 308433

Tel. No.: 65-81263173

Fax No.: 65-63573087

E-mail: Winston_Kon@ttsh.com.sg

ORCiD: https://orcid.org/0000-0002-9693-2587

\footnotetext{
* This paper had previously been presented at $37^{\text {th }}$ Annual Meeting of the Endocrine Society of Taiwan, Taipei, Taiwan, on 20 March 2016 and in the $12^{\text {th }}$ Asia and Oceania Thyroid Association (AOTA) Congress, Busan, Korea, on 17 March 2017.
} 
random spot urine iodine-creatinine ratio and thyroid size by ultrasound imaging, performed by our hospital radiology service, were measured. The volume of the thyroid gland was calculated as the sum of right and left thyroid lobes using ellipsoid formula $0.479 \times$ length $x$ depth $x$ width. Low echogenicity in the thyroid gland was classified into 4 categories as previously described: Grade 0 , diffuse high-amplitude echoes throughout the whole thyroid lobe; Grade 1, low-amplitude non-uniform echoes in the whole or several regions of the thyroid; Grade 2, several sonolucent regions in the thyroid; and Grade 3, no apparent echoes or very low amplitude echoes throughout the whole thyroid. ${ }^{4}$

\section{Laboratory analysis}

\section{Free thyroid hormones and TSH}

Serum free T4 and free T3 were measured by Access ${ }^{\circledR}$ Thyroid kit in a 2-step competitive immunoassay on a Beckman CoulterTM automated platform. Serum TSH was measured by Access ${ }^{\circledR}$ HYPERsensitive ( $3^{\text {rd }}$ generation) chemiluminescent sandwich immunoassay on a Beckman Coulter automated platform.

\section{TRAb Assay}

$\mathrm{TRAb}$ was measured using a third generation M22-biotin based ELISA commercial kit (Euroimmun TRAb Fast ELISA IgG) on the Triturus Analyser. Measurements were performed according to the manufacturer's instructions. TBII is detected by inhibiting the binding of M22 to immobilized recombinant human TSHR. The calibration is standardized against WHO 1995 Standard 90/672 (NIBSC 90/672).

\section{Thyroid Stimulating Immunoglobulin (TSI)}

The thyroid stimulating activity of TSH receptor antibodies is measured by their ability to stimulate susceptible cells to make thyroid adenylate cyclase (cAMP). The immunoglobulin (Ig) fraction of patients' sera is precipitated with a $20 \%$ solution of polyethylene glycol (PEG). 120 $\mu$ of the reconstituted Ig fraction is then incubated with cloned JP-26 cells in a 96-well microtiter culture plate for two hours at $37{ }^{\circ} \mathrm{C}$ in $5 \% \mathrm{CO}_{2} / 95 \%$ air atmosphere, using hypotonic buffer. The supernatants are then collected and assayed for cAMP contents in a radioimmunoassay. Results are expressed as percent increase in patient cAMP production as compared to normal human serum (NHS) cAMP production. The calculation formula for TSI results are expressed as \%: (Patient's cAMP / NHS's cAMP) x 100 $\%$ (Reference range of TSI $=50 \%$ to $179 \% ;>179 \%$ indicate stimulating). Each sample is performed in duplicate and the results averaged. The estimated inter-assay coefficient of variation (CV) of the TSI assay is $10 \%$ to $20 \%$.

\section{Thyroid Peroxidase Antibody}

$\mathrm{TPO} \mathrm{Ab}$ was measured using the commercial kit (ORGENTECDiagnostika GmbHELISA IgG) on the Triturus Analyser. Measurements were performed according to the manufacturer's instructions. The calibration is standardized against the international reference preparation $\mathrm{WHO}$ MRC66/387 for anti-TPO antibodies as $1000 \mathrm{IU} / \mathrm{ml}$.

\section{Urine lodine-Creatinine Ratio (UICR)}

Specimens were sent to Mayo Laboratories. Urine iodine was analysed using inductively coupled plasma mass spectrometry (Elan Dynamic Reaction Cell II; Perkin Elmer) in standard mode using tellurium (Te) as an internal standard. Urine $(60 \mu \mathrm{L})$ was first diluted 1:25 in diluent $(50 \mathrm{mcg} / \mathrm{L} \mathrm{Te}$ and $10 \mathrm{mcg} / \mathrm{L} \mathrm{Rh}$ in $1 \%$ tetramethylammonium hydroxide) and then quantified using an aqueous acidic calibration. The analytical measuring range was $10-40,000 \mathrm{mcg} / \mathrm{L}$. Urine creatinine was measured using Roche assay, based on the enzymatic conversion of creatinine by creatininase, creatinase, and sarcosine oxidase to glycine, formaldehyde and hydrogen peroxide. Catalyzed by peroxidase, the liberated hydrogen peroxide reacts with 4-aminophenazone and HTIBa to form a quinone imine chromogen. The colour intensity of the quinone imine chromogen formed is directly proportional to the creatinine concentration in the reaction mixture, utilizing inductively coupled plasma mass spectrometry (ICP-MS) for iodine quantification in urine. This was normalized to urine creatinine, performed by enzymatic colorimetric assay (Roche).

\section{Descriptive analysis}

The baseline clinical characteristics and initial thyroid function response from all 5 patients are tabulated together with the reference range of each test. When a serum result was expressed as greater or less than a numerical limit, that value of limit was utilized. For each patient, thyroid function (fT4, fT3, TSH), TRAb, TSI, anti-TPO Ab titre, and CMZ dose were summarised graphically across the follow-up calendar time.

\section{RESULTS}

Patients presented with typical symptoms such as weight loss, increased appetite, palpitations, heat intolerance, diarrhoea and tremors. Patients 1 and 4 presented with complications of atrial fibrillation and thyrocardiac failure. Baseline demographics, thyroid function, thyroid volume and echogenicity, starting CMZ dose and initial thyroid function response are shown in Table 1. In all 5 patients, $\mathrm{CMZ}$ was started at doses equivalent to, or below, the methimazole (MMI)-equivalent starting dose (CMZ 10 mg equivalent to MMI $6 \mathrm{mg}$ ) suggested for the degree of fT4 elevation by the 2016 American Thyroid Association Guidelines. ${ }^{1}$ The initial free thyroxine mean was $41.5 \mathrm{pM}$, range $25-69 \mathrm{pM}$. The mean thyroid volume measured by ultrasound was $11.2 \mathrm{ml}$, range 9.0-15.6 ml. All patients remained clinically agoitrous throughout the course of follow-up. The range of initial TSI was $1487 \%$ to $>4444$ $\%$. Serum fT4 plunged to low-normal or hypothyroid levels within 3.6 to 9.3 weeks of initiating oral CMZ 5 to $15 \mathrm{mg}$ daily and were subsequently modulated by fine adjustments in $\mathrm{CMZ}$ dosage.

Our 5 patients' follow-up ranged from 14.7 months to 121.7 months (mean of 66.27 months, SD of 39.3 months). Their long-term biochemical course in response to $\mathrm{CMZ}$ treatment are shown in Figures 1-5. In all instances, the date of the dispensation of $C M Z$ was verified to be the same as the date of prescription, suggesting patient compliance to therapy. In patients \#1 and \#2, whilst on ATD treatment, serum TSH was seen to remain inappropriately suppressed despite fT4 decreasing to and remaining at low normal concentrations, whilst fT3 levels remained normal (Figures 1-2). In patient \#2, TSH was seen to be restored to within the lower half of reference range (its suppression was overcome) at 
Table 1. Baseline Clinical Characteristics and Initial Thyroid Function Response After Starting Oral Carbimazole (CMZ)

\begin{tabular}{|c|c|c|c|c|c|c|c|c|c|c|c|c|c|}
\hline Patient & $\begin{array}{l}\text { Ethnicity, } \\
\text { Age/Gender }\end{array}$ & $\begin{array}{c}\text { USS } \\
\text { Thyroid } \\
\text { volume }\end{array}$ & $\begin{array}{c}\text { Hypoecho- } \\
\text { genicity } \\
\text { Grade }^{a}\end{array}$ & $\begin{array}{l}\text { Initial } \\
\text { fT4 }\end{array}$ & $\begin{array}{c}\text { Initial } \\
\text { TSH }\end{array}$ & $\begin{array}{l}\text { Initial } \\
\text { TRabT }\end{array}$ & $\begin{array}{c}\text { Initial } \\
\text { TSI }\end{array}$ & $\begin{array}{l}\text { Initial } \\
\text { CMZ } \\
\text { dose }\end{array}$ & $\begin{array}{l}\text { Time from } \\
\text { Starting } \\
\text { CMZ to } \\
\text { Next TFT }\end{array}$ & $\begin{array}{l}\text { Next } \\
\text { fT4 }\end{array}$ & $\begin{array}{l}\text { Next } \\
\text { fT3 }\end{array}$ & Next TSH & $\begin{array}{c}\text { Random } \\
\text { Urine } \\
\text { lodinel } \\
\text { Cr Ratio }\end{array}$ \\
\hline & (yrs) & $\left(\mathrm{cm}^{3}\right)$ & & (pM) & $(\mathrm{mlU} / \mathrm{L})$ & (IU/L) & $(\%)$ & $(\mathrm{mg} / \mathrm{d})$ & (weeks) & $(\mathrm{pM})$ & (pM) & $(\mathrm{mlU} / \mathrm{L})$ & $(\mathrm{mcg} / \mathrm{g})$ \\
\hline 1 & Chinese / 56 / F & 14.3 & 1 & 69 & 0.03 & 5.4 & 1487 & 15 & 9.3 & 6 & 3.7 & 0.02 & 167 \\
\hline 2 & Chinese / 81/ F & 9.1 & 1 & 28 & $<0.01$ & $>40.0$ & $>4444$ & 5 & 9.0 & 8 & 3.7 & 0.01 & 192 \\
\hline 3 & Chinese / 55 / F & 7.2 & 1 & 49 & 0.02 & $>30.0$ & $>4444$ & 15 & 4.0 & 5 & 3.8 & 0.02 & - \\
\hline 4 & Chinese / $72 / \mathrm{M}$ & 15.6 & 1 & 25 & 0.06 & 34.3 & $>4000$ & 10 & 3.6 & 6 & 4.6 & 0.06 & 145 \\
\hline 5 & Chinese / 82 / M & 9.0 & 0 & 29 & 0.05 & 31.2 & 3160 & 10 & 5.3 & 6 & 3.8 & 0.18 & 108 \\
\hline Exp & ected range & $<15$ & & $8-21$ & $0.34-5.64$ & $<0.4$ & $80-179$ & & & $8-21$ & $3.5-6.0$ & $0.34-5.64$ & $26-705$ \\
\hline
\end{tabular}

a Grade 0, diffuse high-amplitude echoes throughout the whole thyroid lobe; Grade 1, low-amplitude non-uniform echoes in the whole or several regions of the thyroid; Grade 2, several sonolucent regions in the thyroid; and Grade 3, no apparent echoes or very low amplitude echoes throughout the whole thyroid.
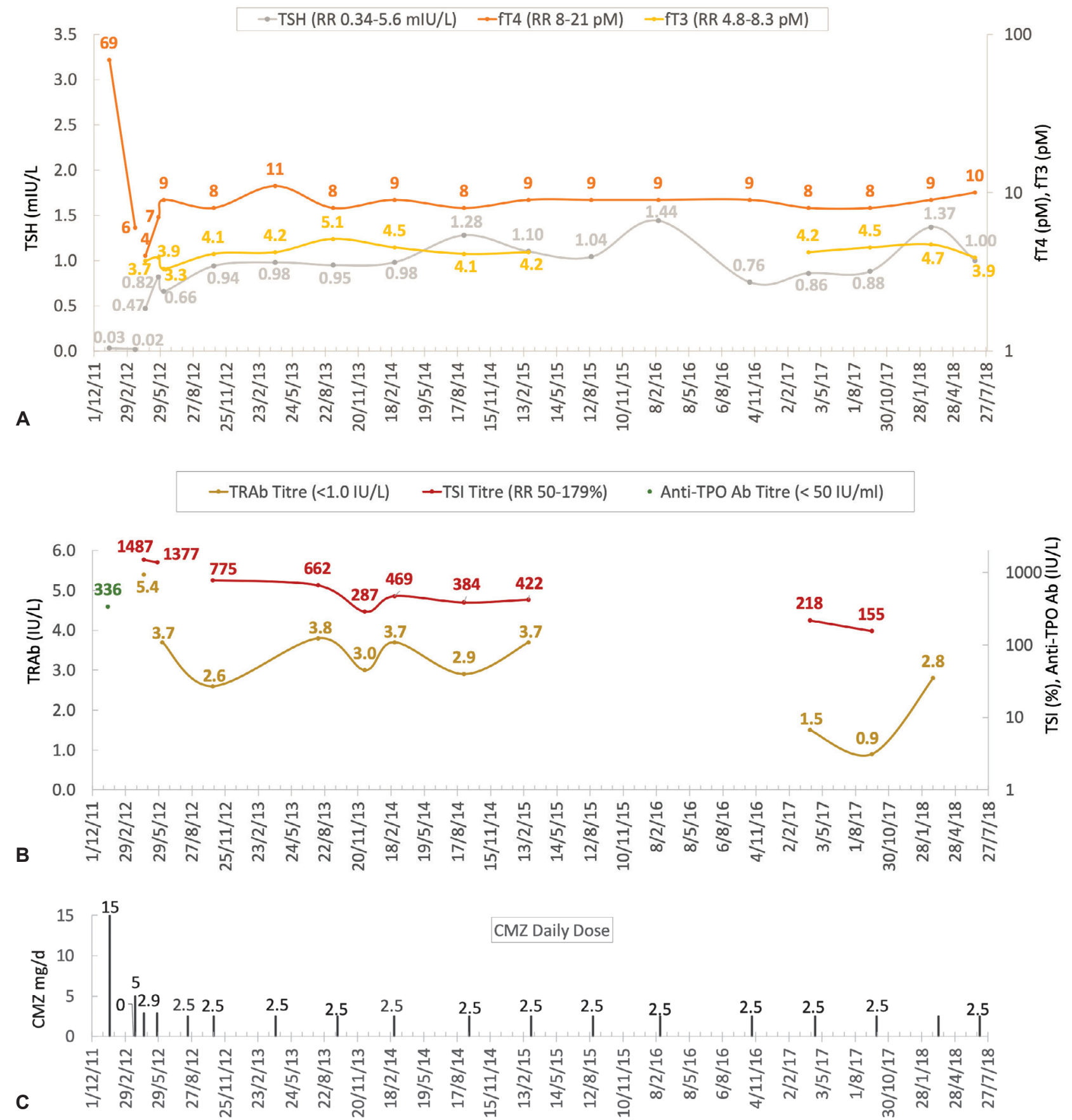

Figure 1. Patient 1 clinical course (A) thyroid function; (B) serum TSH receptor antibody (TRAb) and thyroid stimulating immunoglobulin (TSI) levels; (C) carbimazole (CMZ) therapy-average daily dose. From 22.3.12-25.5.12 (9.4 weeks), serum TSH remained inappropriately suppressed or inappropriately normal in the presence of low serum fT4. 

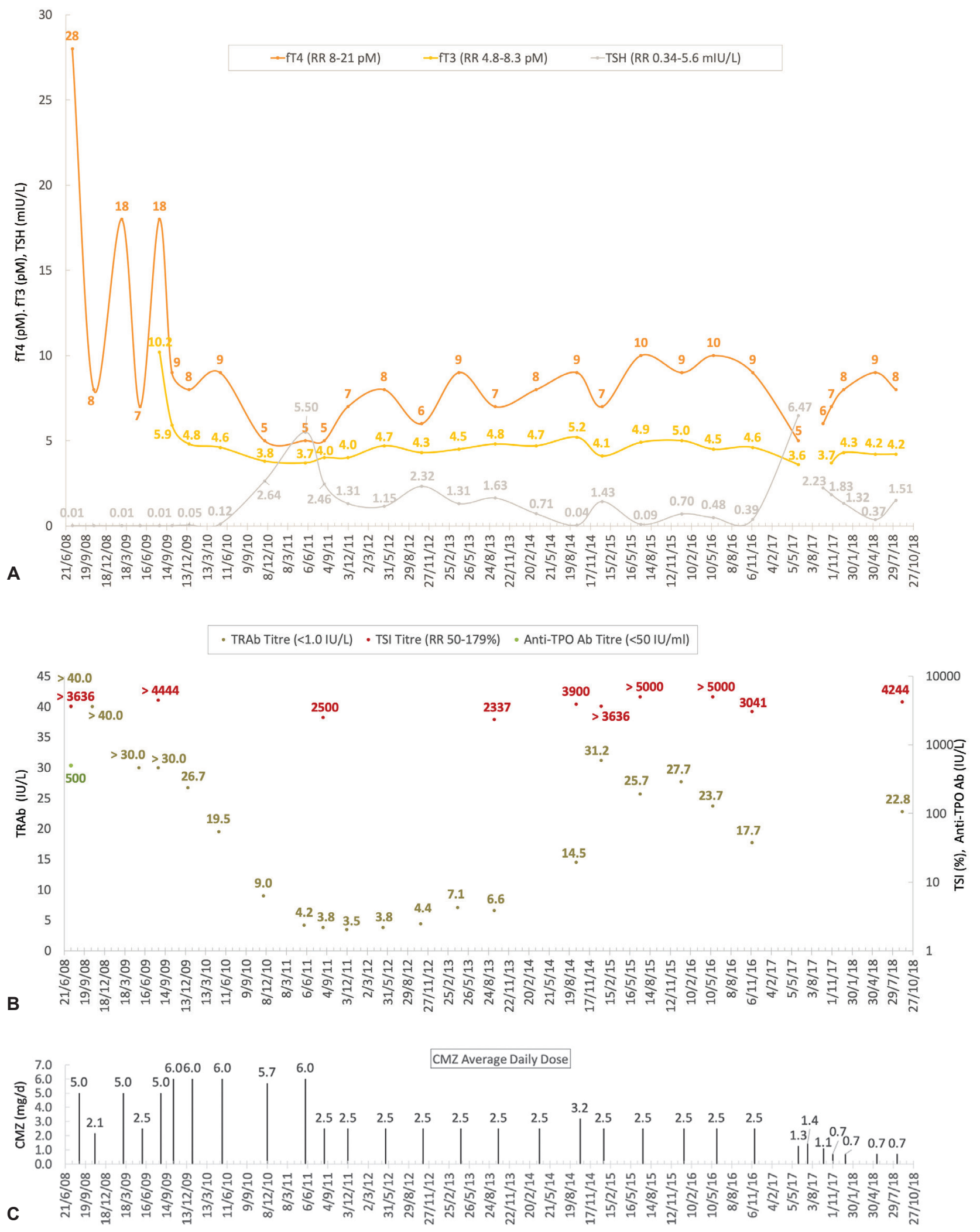

Figure 2. Patient 2 clinical course (A) thyroid function; (B) serum TSH receptor antibody (TRAb) and thyroid stimulating immunoglobulin (TSI) levels; (C) carbimazole (CMZ) therapy-average daily dose. Between 24.10.08 and 8.10.09, fT4 showed a "yo-yo" pattern with small dose adjustments of CMZ. Between 25.11.10 and 30.06.15, TFT showed "central hypothyroid" pattern.

concomitant fT4 values that were below normal (Figure 2). These patterns resembled "central hypothyroid" patterns. As all patients were non-pregnant, dose of CMZ was adjusted to keep serum fT3 mid-normal as the first priority.
All our patients preferred and were maintained on prolonged low dose $\mathrm{CMZ}$, in averaged daily doses ranging from $0.7 \mathrm{mg}$ to $3.2 \mathrm{mg}$. Remarkably, in the long-term, patient \#2 required the lowest dose of only CMZ $2.5 \mathrm{mg}$ 

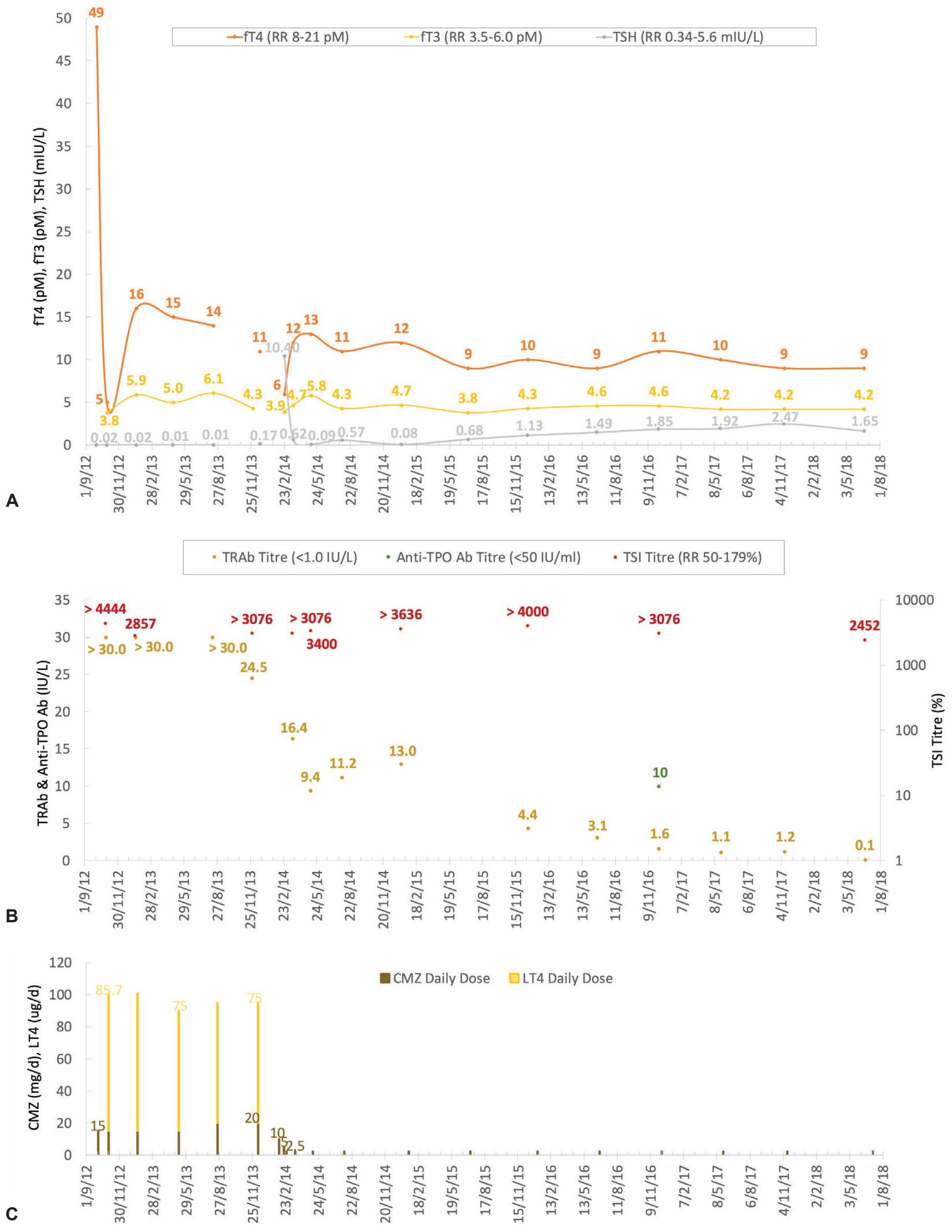

Figure 3. Patient 3 clinical course (A) thyroid function; (B) serum TSH receptor antibody (TRAb) and thyroid stimulating immunoglobulin (TSI) levels; $(\mathrm{C})$ carbimazole (CMZ) therapy-average daily dose. Patient received block and replace, followed by CMZ only therapy. Although TRAb levels demonstrated a downtrend, paired TSI activity remained discordantly elevated.

twice per week (averaged to $0.7 \mathrm{mg}$ daily) to maintain euthyroidism, despite having persistently elevated TSI levels at 24 times above upper limit of normal (Figure 2).

\section{DISCUSSION}

We present 5 patients with newly diagnosed Graves' hyperthyroidism whose serum fT4 plunged to unexpectedly 


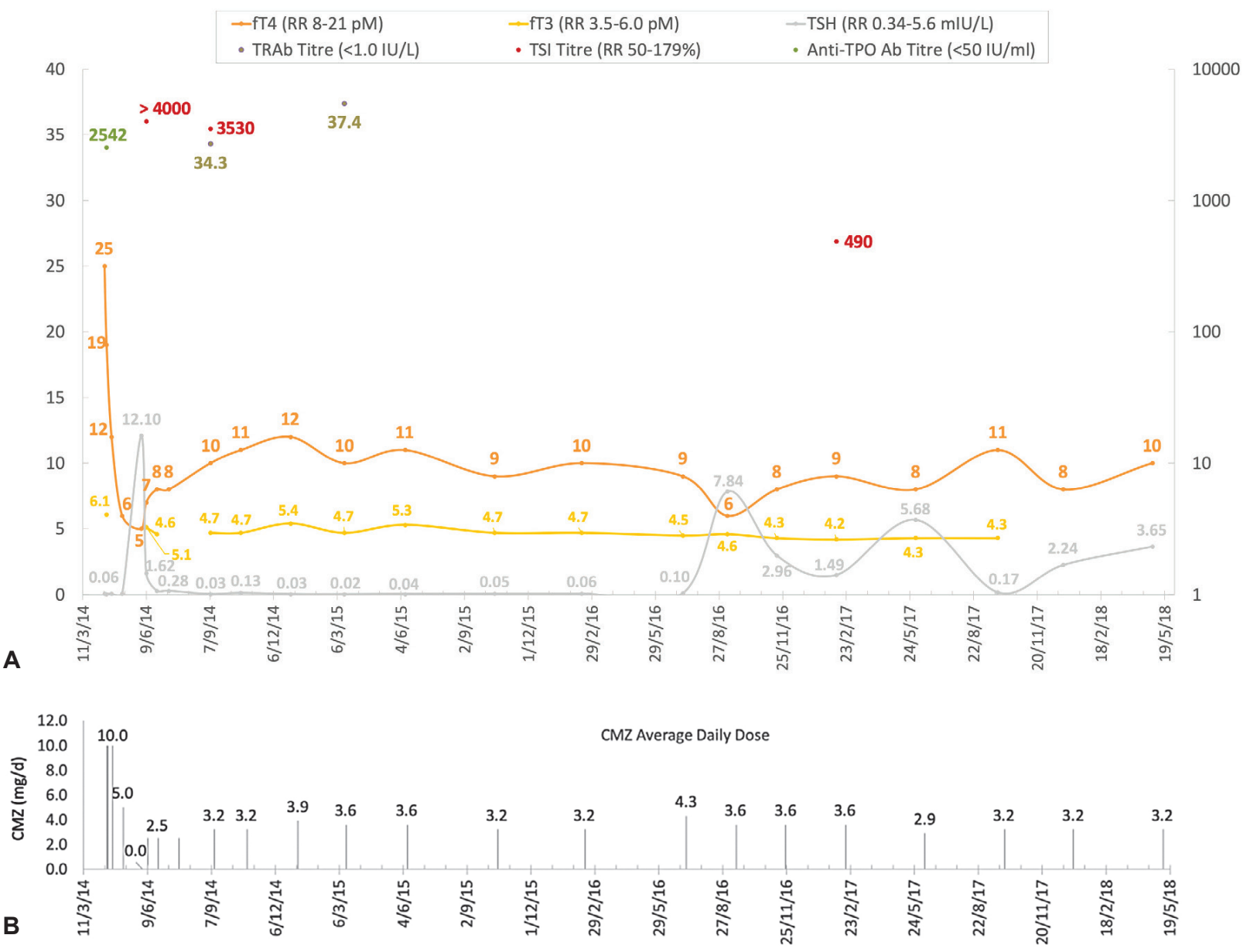

Figure 4. Patient 4 clinical course (A) thyroid function, serum TSH receptor antibody (TRAb) and thyroid stimulating immunoglobulin (TSI) levels; (B) carbimazole (CMZ) therapy-average daily dose. On 7 weeks of $\mathrm{CMZ} 10 \mathrm{mg}$ od, patient became primary hypothyroid. CMZ was stopped for 1 week, then resumed on $2.5 \mathrm{mg}$ daily to avoid rebound thyrotoxicosis.

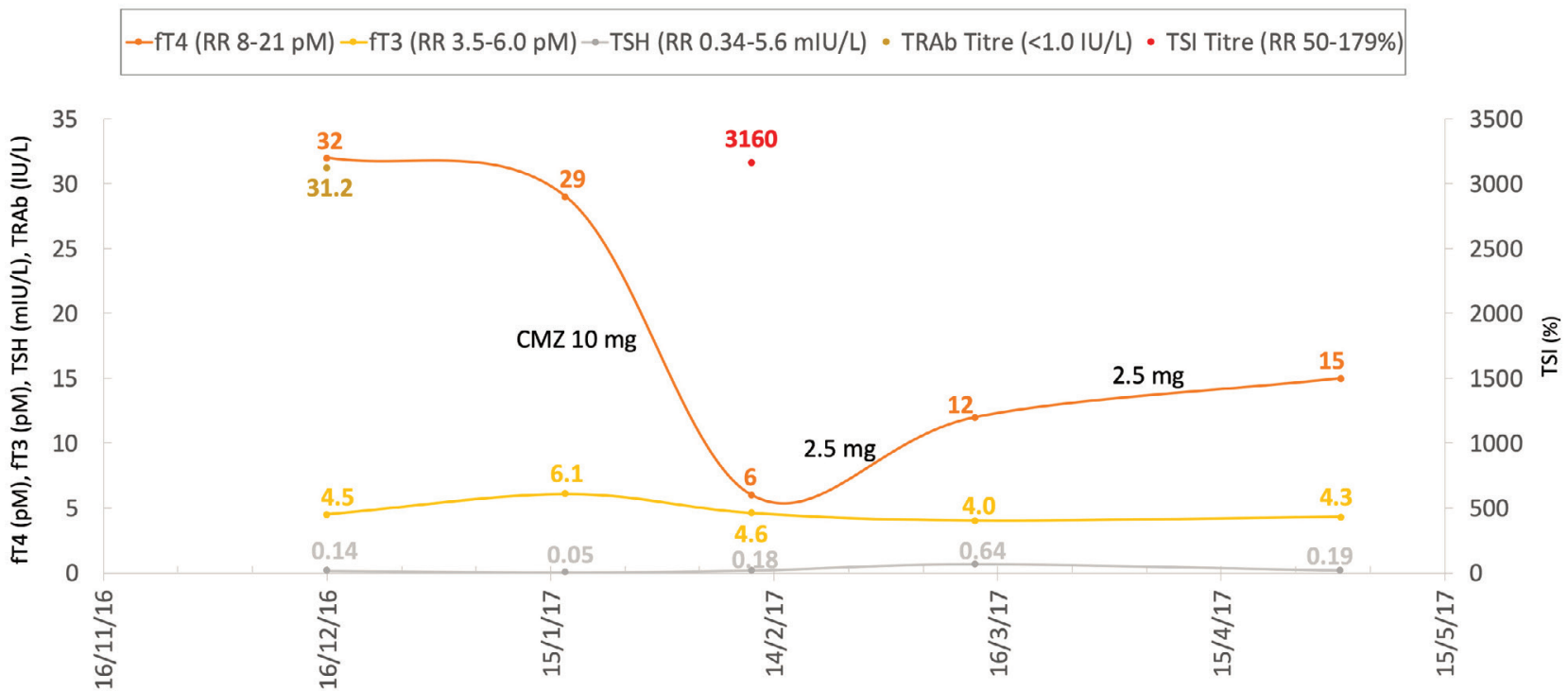

Figure 5. Patient 5 thyroid function course in response to carbimazole (CMZ) therapy. On CMZ $10 \mathrm{mg}$ od for 3.6 weeks, patient became hypothyroxinemic; CMZ was not stopped but decreased to $2.5 \mathrm{mg}$ daily, to avoid rebound thyrotoxicosis.

low levels after commencing CMZ at doses equivalent to, or below, that suggested for the degree of fT4 elevation by the 2016 American Thyroid Association Guidelines. ${ }^{1}$ All 5 patients demonstrated absence of goiter with remarkably elevated TRAb and TSI levels around the time of diagnosis. In a retrospective multivariate analysis by Choi et al., of 99 patients with new onset Graves' disease, high level of fT4, high titre of TRAb and absence of goiter were 
associated with rapid responsiveness to methimazole treatment. $^{2}$ Their study, together with our case series, suggest that Graves' patients presenting with normal-sized thyroid glands and markedly elevated TSI levels predict a "rapid responder" phenotype to conventional doses of ATD. Moreover, we observed the perplexing profile of prolonged suppressed, or inappropriately normal, TSH despite concomitantly low-normal or low serum fT4 during the course of ATD treatment, when serum fT3 was low to normal.

Dalan et al., reported on an agoitrous Graves' patient with markedly elevated TRAb who rapidly became hypothyroxinemic 2 weeks after being treated with a conventional dose of CMZ (Appendix A, reproduced with permission). ${ }^{3}$ Presence of thyroid stimulating blocking antibody (TSBAb) was excluded. After CMZ therapy was discontinued for a week, a thyroid uptake scan demonstrated $63 \%$ uptake at 4 hours, and $42 \%$ uptake at 24 hours, with $24-\mathrm{hr}$ minus 4 -hr delta RAIU of $-21 \%$, or remarkably high iodine turnover.

Similarly, Gemma et al., reported that the difference between 3-hour and 24-hour RAIU predicted rapidity of response to MMI therapy in Graves' patients. ${ }^{5}$ They found that 24-hr minus 3-hr delta RAIU was significantly lower in rapid responders (TFT was normal or low within 1 month) than gradual responders. Delta RAIU was negatively correlated with the reduction in serum fT4 level at two weeks after MMI initiation and positively correlated with the biological half-life of intrathyroidal iodine.

TSH and TSI drive thyroidal iodine turnover. In 1944, Astwood and Bissell demonstrated that when normal rats were administered blocking doses of propylthiouracil (PTU) that rendered them hypothyroid, severe thyroidal iodine depletion occurred within days despite adequate iodine intake. ${ }^{6}$ Upon discontinuing ATD, the thyroid gland's ability to re-accumulate iodine after it had been depleted was suppressed by thyroxine treatment or hypophysectomy, presumably by preventing rise of TSH. When hypophesectomy was performed before PTU was given, or if thyroxine was concomitantly administered with PTU, thyroidal iodine loss was prevented or ameliorated in a graded manner. ${ }^{6}$ It is now well established that elevated serum TSH or TSI increases thyroidal iodide uptake, increases $\mathrm{T} 3$ formation relative to that of $\mathrm{T} 4$, and leads to increased iodine turnover via its return to the circulation as thyroid hormone, with relatively more T3 than T4 secreted compared to normal. ${ }^{7-9}$ Hence a high serum TSI level may be regarded as a marker for increased iodine turnover.

The intra-thyroidal iodine pool seen in untreated and treated Graves' thyroids are lower than those of normal thyroids. ${ }^{10,11}$ In 1975, Larsen compared the thyroidal iodine content of 13 patients with Graves' disease who had undergone thyroidectomy to that of 11 normal human thyroid glands. ${ }^{10}$ He found that the mean thyroidal iodine content of 2 patients who had received only propranolol (450 $\mu \mathrm{g} / \mathrm{g}$ wet weight of thyroid tissue) was lower than normal $(630 \pm 60 \mu \mathrm{g} / \mathrm{g})$, but those who had received specific ATD treatment prior to surgery had the lowest levels. In particular, 3 of these patients were found to have very low thyroidal iodine $(100 \pm 26 \mu \mathrm{g} / \mathrm{g})$ and markedly low serum T4 and low-normal serum T3 levels. Remarkably, 2 of these patients had non-elevated serum TSH levels.

ATD may reversibly or irreversibly inhibit thyroid peroxidase (TPO) catalyzed iodination, depending on the relative intra-thyroidal concentrations of iodine and ATD. ${ }^{11-13}$ At low intrathyroidal iodine level, iodination inhibition by ATD is irreversible, but an increase in iodine concentration competitively overcomes the inhibition. It is considered that rapid responders with small thyroid volume and thus small intrathyroidal iodine pool require a markedly elevated TSI level and a fast iodine turnover rate to maintain elevated thyroid hormone levels. The high iodine turnover in turn, contributes to the small iodine pool.

When relatively high doses of ATD are started, the intrathyroidal ATD to iodide concentration ratio is increased, almost complete blockage of iodide organification ensues, leading to a rapid decrease in serum fT4 relative to serum fT3. Intriguingly, Taurog observed from his animal experiments, that "the change from reversible to irreversible inhibition of iodination with both propylthiouracil and methimazole occurred with seemingly slight elevations in the concentrations of these drugs."12 Perhaps this relates clinically to the marked swing in fT4 levels with slight changes in ATD dose, seen initially for example, in patient 2 (Figure 2).

Azizi reported that Graves' hyperthyroidism responds more rapidly to MMI in an iodine-deficient area (Teheran) compared with in an iodine-sufficient area (Boston), where urinary iodine/creatinine ratio above $50 \mathrm{~g} / \mathrm{g}$ represented iodine-sufficiency. ${ }^{14}$ In a subsequent study he reported that less than the usual recommended doses of MMI or PTU caused a rapid decline of thyroid hormone indices in patients residing in Teheran. ${ }^{15}$ In opposite contrast, patients with type 1 amiodarone-induced thyrotoxicosis may require higher than usual doses of ATD, because of the drug-derived iodine load.

All four of our patients in whom we performed random urine iodine/creatine ratio had values above $100 \mu \mathrm{g} / \mathrm{g}$ (Mayo Lab lower reference value $70 \mu \mathrm{g} / \mathrm{g}$ ), suggesting that the rapid-responder phenotype may also occur in the presence of adequate iodine intake, when small thyroid and markedly elevated TSI titre are concomitantly present.

Besides driving high thyroidal iodine turnover, it is speculated that a high TRAb level may downregulate pituitary TSH secretion by an ultra-short negative feedback loop by acting on the pituitary TSH receptor (TSHR). ${ }^{16,17}$ The pituitary TSHR, expressed in the human anterior pituitary on folliculo-stellate cells, lies outside the blood-brain barrier and is therefore accessible to these autoantibodies. ${ }^{18}$ As the pituitary TSHR is also recognized by TSI, this interaction plausibly explains the prolonged serum TSH suppression seen in patients with Graves' subclinical hyperthyroidism. ${ }^{19}$

In the course of follow-up, our patients demonstrated a discordant pattern of prolonged suppressed or lownormal TSH with corresponding low-normal or low fT4 levels. The concomitant fT3 levels were normal, hence the inappropriately low TSH is not due to T3-toxicosis. 
Thus, persistent highly elevated serum TRAb levels suppressing serum TSH by a short negative feedback loop on pituitary thyrotrophs, offers an alternative explanation to a "delayed recovery" of thyrotrophs, especially if serum TSH remains inappropriately low after 4-6 weeks of relief of endogenous or exogenous hyperthyroidism. ${ }^{20}$ This short-loop suppression is conceivably overridden when serum fT4 decreases further consequent upon further increase in ATD dose, leading to a rise in serum $\mathrm{TSH}$, i.e., classical biochemical primary hypothyroidism (Appendix B).

Our cases demonstrate long-term maintenance of euthyroidism on low dose (patient \#3) or ultra-low dose (patient \#2) CMZ despite the presence of persistently and concurrently highly elevated TSI levels. We speculate that euthyroidism could be maintained on such low doses of CMZ because of low intrathyroidal iodine content, a mechanism also alluded to by Lauberg. ${ }^{21}$ From personal communication, Dalan's case was subsequently maintained euthyroid on CMZ $2.5 \mathrm{mg}$ on alternate days, and could not be weaned off CMZ because of thyrotoxic relapse.

Our small case series together with Dalan's case report suggest that Graves' patients with rapid-responder phenotype require atypically lower initial ATD dosing. If started on conventional doses (10-20 mg CMZ or equivalent), they may become hypothyroxinemic in 4-6 weeks. For such patients, we suggest the initial ATD dose should be lower than usually prescribed, and the follow-up interval shorter than usually arranged. When serum fT4 are at hypothyroid levels, the period of ATD discontinuation should not be too prolonged so as to avoid rebound thyrotoxicosis.

\section{Study Limitations}

Our case series is limited by the small number of patients, although 4 of the patients had extended follow-up. Future prospective case-controlled studies examining clinical characteristics, therapy and monitoring of rapidresponder Graves' thyrotoxicosis should be undertaken, to accumulate experience and evidence.

\section{CONCLUSION}

Patients with newly diagnosed Graves' hyperthyroidism who have small thyroid glands and markedly elevated TSI titres appear to be "ATD dose sensitive." Free T4 may swing markedly with small dose adjustments of ATD, or a "central hypothyroid" pattern of TFT may be seen. We suggest finer ATD dose titration at closer follow-up intervals to achieve biochemical euthyroidism, guided by monitoring TFT, fT3 and TRAb or TSI.

\section{Ethical Considerations}

Ethics approval was obtained by the authors.

\section{Statement of Authorship}

All authors certified fulfillment of ICMJE authorship criteria.

\section{Author Disclosure}

All authors declared no conflicts of interest.

\section{Funding Source}

None.

\section{References}

1. Ross DS, Burch HB, Cooper DS, et al. 2016 American Thyroid Association Guidelines for diagnosis and management of hyperthyroidism and other causes of thyrotoxicosis. Thyroid. 2016;26(10):1343-1421. PMID: 27521067. https://doi.org/10.1089/thy.2016.0229.

2. Choi HS, Yoo WS. Free thyroxine, anti-thyroid stimulating hormone receptor antibody titres, and absence of goiter were associated with responsiveness to methimazole in patients with new onset Graves' disease. Endocrinol Metab. 2017; 32(2):281-7. PMID: 28685517. PMCID: PMC5503874. https://doi.org/10.3803/EnM.2017.32.2.281.

3. Dalan R, Leow MKS, Ng CE. High iodine (substrate) turnover Graves' disease: The intriguing 'rapid-responder' variant of thyrotoxicosis. Ann Clin Biochem 2008;45(Pt6):612-5.PMID:18941129. https://doi.org/10.1258/acb.2008.008098.

4. Takeshima $\mathrm{K}$, Inaba $\mathrm{H}$, Furukawa $\mathrm{Y}$, et al. Elevated serum immunoglobulin G4 levels in patients with Graves' disease and their clinical implications. Thyroid 2014;24(4):736-43. PMID: 24256421 https://doi.org/10.1089/thy.2013.0448

5. Gemma R, Nakamura H, Mori T, Andoh S, Suzuki Y, Yoshimi T. The change in 123I-uptake between 3- and 24-hours is useful in predicting early response to methimazole in patients with Graves' disease. Endocr J. 1996;43(1):61-6. PMID: 8732453. https://doi.org/10.1507/ endocrj.43.61.

6. Astwood EB, Bissell A. Effect of thiouracil on the iodine content of the thyroid gland. Endocrinology. 1944;34:282-96. https://doi.org/10.1210/ endo-34-4-282.

7. Dunn JT, Dunn AD. Update on intrathyroidal iodine metabolism. Thyroid. 2001;11(5):407-14.PMID:11396699. https://doi.org/10.1089/ 105072501300176363

8. Lauberg P, Vestergaard H, Nielsen S, et al. Sources of circulating 3,5,3'- triiodothyronine in hyperthyroidism estimated after blocking of type 1 and type 2 iodothyronine deiodinases. J Clin Endocrinol Metab. 2007;92(6):2149-56. PMID: 17389703. https://doi.org/10.1210/ jc. 2007-0178.

9. Abuid J, Larsen PR. Triidothyronine and thyroxine in hyperthyroidism. Comparison of the acute changes during therapy with antithyroid agents. J Clin Invest. 1974;54(1):201-8. PMID: 4134836. PMCID: PMC301541. https://doi.org/10.1172/JCI107744.

10. Larsen PR. Thyroidal triiodothyronine and thyroxine in Graves disease: Correlation with presurgical treatment, thyroid status and iodine content. J Clin Endocrinol Metab. 1975;41(06):1098-104. PMID: 54364. https://doi.org/10.1210/jcem-41-6-1098.

11. Engler H, Taurog A, Luthy C, Dorris ML. Reversible and irreversible inhibition of thyroid peroxidase-catalyzed iodination by thioureylene drugs. Endocrinology. 1983;112(1):86-95. PMID: 6847836. https://doi. org/10.1210/endo-112-1-86.

12. Taurog A. The mechanism of action of the thioureylene antithyroid drugs. Endocrinology.1976;98(4):1031-46.PMID:1278093. https://doi. org/10.1210/endo-98-4-1031.

13. Taurog A, Dorris ML, Guziec FS Jr. Metabolism of 35S- and 14C-labelled 1-methyl-2-mercaptoimidazole in vitro and in vivo. Endocrinology. 1989;124(1):30-9. PMID: 2535809. https://doi.org/10.1210/endo-124-1-30.

14. Azizi F. Environmental iodine intake affects the response to methimazole in patients with diffuse toxic goiter. J Clin Endocrinol Metab. 1985;61(2):374-7. PMID: 3839244. https://doi.org/10.1210/ jcem-61-2-374.

15. Azizi F. Medical treatment of toxic goiter in an area of iodine deficiency. MJIRI 1988;2(2):119-22. http://mjiri.iums.ac.ir/article-1-1264-en.pdf.

16. Prummel MF, Brokken LJS, Wiersinga WM. Ultra-short-loop feedback of thyrotropin secretion. Thyroid. 2004;14(10): 825-9. PMID: 15588378. https://doi.org/10.1089/thy.2004.14.825.

17. Brokken LJ, Scheenhart JW, Wiersinga WM, Prummel MF. Suppression of serum TSH by Graves' Ig: Evidence for a functional pituitary TSH receptor. J Clin Endocrinol Metab. 2001;86(10): 4814-7. PMID: 11600546. https://doi.org/10.1210/jcem.86.10.7922.

18. Prummel MF, Brokken LJ, Meduri G, Misrahi M, Bakker O, Wiersinga WM. Expression of the thyroid-stimulating hormone receptor in the folliculo-stellate cells of the human anterior pituitary. J Clin Endocrinol Metab. 2000;85(11):4347-53. PMID:11095478. https://doi.org/10.1210/ jcem.85.11.6991.

19. Brokken LJS, Wiersinga WM, Prummel MF. Thyrotropin receptor autoantibodies are associated with continued thyrotropin suppression in treated euthyroid Graves' disease patients. J Clin Endocrinol Metab. 2003;88:4135-8. https://doi.org/10.1210/jc.2003-030430.

20. Vagenakis AG, Braverman LE, Azizi F, Portnay GI, Ingbar SH. Recovery of pituitary thyrotrophic function after withdrawal of prolonged thyroid-suppression therapy. N Engl J Med. 1975;293(14):681-4. PMID: 808728. https://doi.org/10.1056/NEJM197510022931402.

21. Lauberg P. Remission of Graves' disease during anti-thyroid drug therapy. Time to reconsider the mechanism? Eur J Endocrinol. 2006;155(6):783-6. PMID: 17132745. https://doi.org/10.1530/eje.1.02295. 


\section{APPENDICES}

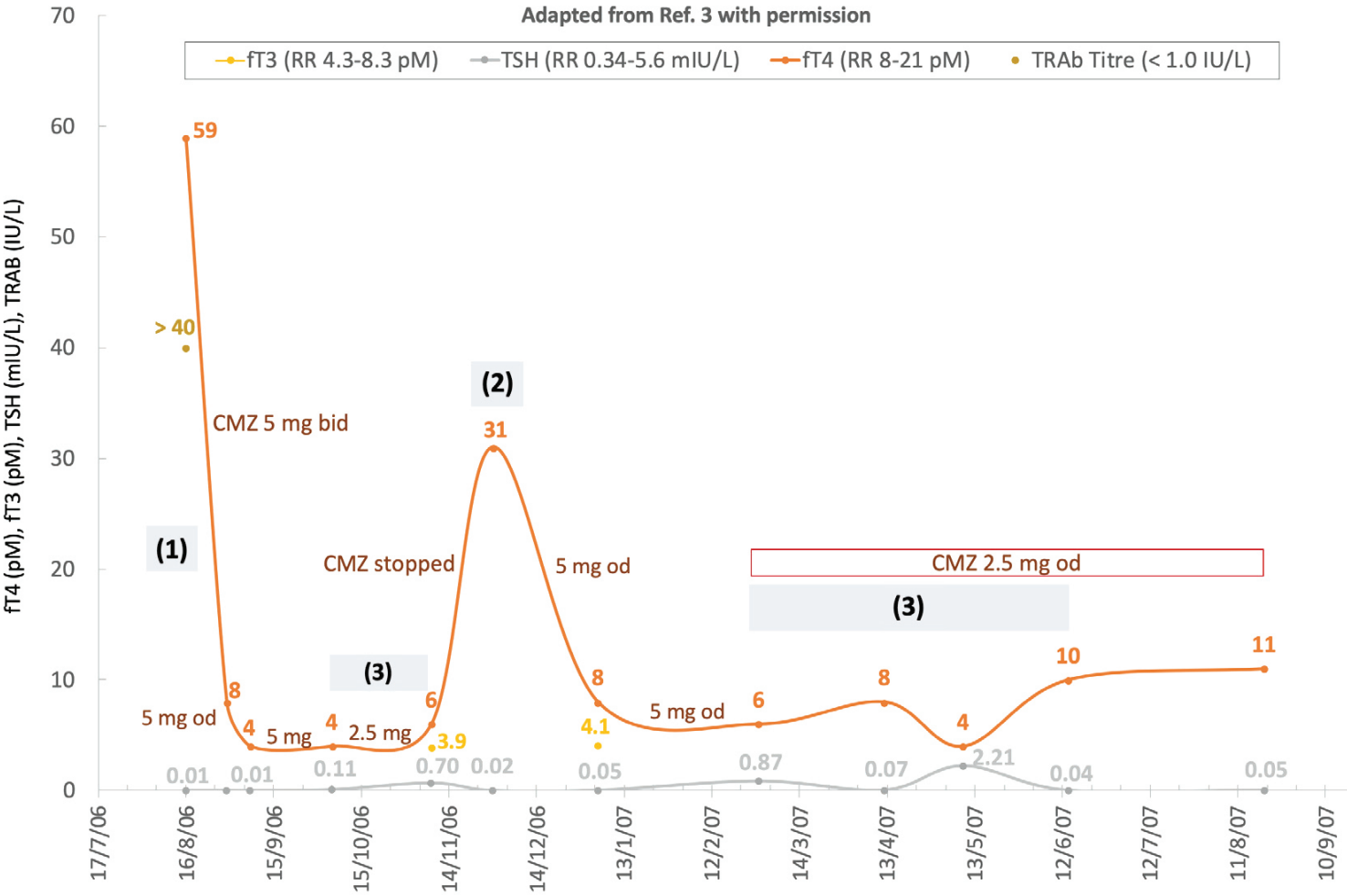

Appendix A. High-iodine-turnover Graves' patient displaying (1) rapid response to low dose CMZ; (2) rapid rebound thyrotoxicosis after stopping CMZ; (3) "central hypothyroid" TFT pattern.

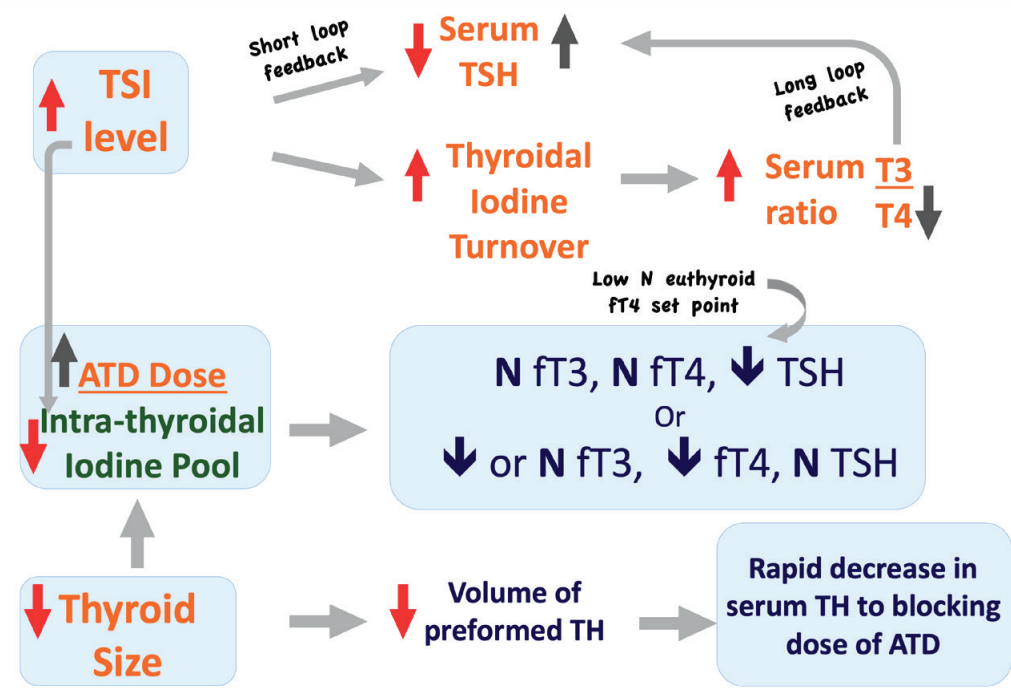

Appendix B. Proposed Schematic of Small Thyroid-High TSI Rapid-Responder Graves' Pathophysiology.

Authors are required to accomplish, sign and submit scanned copies of the JAFES Author Form consisting of: (1) Authorship Certification, that authors contributed substantially to the work, that the manuscript has been read and approved by all authors, and that the requirements for authorship have been met by each author; (2) the Author Declaration, that the article represents original material that is not being considered for publication or has not been published or accepted for publication elsewhere, that the article does not infringe or violate any copyrights or intellectual property rights, and that no references have been made to predatory/ suspected predatory journals; (3) the Author Contribution Disclosure, which lists the specific contributions of authors; and (4) the Author Publishing Agreement which retains author copyright, grants publishing and distribution rights to JAFES, and allows JAFES to apply and enforce an Attribution-Non-Commercial Creative Commons user license. Authors are also required to accomplish, sign, and submit the signed ICMJE form for Disclosure of Potential Conflicts of Interest. For original articles, authors are required to submit a scanned copy of the Ethics Review Approval of their research as well as registration in trial registries as appropriate. For manuscripts reporting data from studies involving animals, authors are required to submit a scanned copy of the Institutional Animal Care and Use Committee approval. For Case Reports or Series, and Images in Endocrinology, consent forms, are required for the publication of information about patients; otherwise, appropriate ethical clearance has been obtained from the institutional review board. Articles and any other material published in the JAFES represent the work of the author(s) and should not be construed to reflect the opinions of the Editors or the Publisher. 